\title{
Conformational Analysis of Hexakis-Methylamine Nickel(II) Complex on the Basis of Computational Group Theory and Density Functional Theory
}

\author{
Hiroshi SAKIYAMA, ${ }^{\mathrm{a},}{ }^{,}$Katsushi WAKI, \\ ${ }^{a}$ Department of Material and Biological Chemistry, Faculty of Science, Yamagata University, \\ Kojirakawa 1-4-12, Yamagata 990-8560, Japan \\ ${ }^{b}$ Department of Mathematical Sciences, Faculty of Science, Yamagata University, \\ Kojirakawa 1-4-12, Yamagata 990-8560, Japan \\ *e-mail: saki@sci.kj.yamagata-u.ac.jp
}

(Received: March 5, 2014; Accepted for publication: May 15, 2014; Advance publication: August 15, 2014)

Computational group theory (CGT) method investigations have been conducted for a hexakis-methylamine nickel(II) complex cation $\left[\mathrm{Ni}\left(\mathrm{CH}_{3} \mathrm{NH}_{2}\right)_{6}\right]^{2+}$ [hexakis(methylamine- $\mathrm{K} N$ )nickel(II) dication] to find 54 possible conformers. Considering all the conformers, six conformers have been finally obtained after optimization based on the Density Functional Theory (DFT) computations. The most stable conformer has been found to be a helical conformer ( $C_{1}$ symmetry), which is suitable for avoiding steric repulsion between adjacent ligands. A related zinc(II) complex $\left(\left[\mathrm{Zn}\left(\mathrm{CH}_{3} \mathrm{NH}_{2}\right)_{6}\right]^{2+}\right)$ has also been investigated, and the same conformer was found to be the most stable. Since the energy differences among the conformers have been found to be very small, the conformers are thought to be mixed at room temperature, and the dominant species are thought to be changeable by environment for both complexes.

Keywords: Computational group theory (CGT) method, Hexakis-methylamine complex, Nickel(II) complex, Zinc(II) complex, Conformational analysis, DFT computation

\section{Introduction}

What determines the molecular conformation is one of the important issues in controlling molecular structures of the coordination compounds. The slight distortion around the central metal ion influences the sign of the zero-field splitting (ZFS) [1] and it will determine the magnetic behavior [2]. For example, the sign of the ZFS of an octahedral nickel(II) complex is expected to be positive when the coordination geometry is tetragonally elongated, but negative when tetragonally compressed [1].

Interligand hydrogen bond is one of the important factors in determining molecular geometry and molecular conformation. For example, the structure of an octahedral nickel(II) complex $\left[\mathrm{Ni}(\mathrm{DMF})_{6}\right]^{2+}(\mathrm{DMF}=N, N$-dimethylformamide $)[3]$ is determined by the interligand hydrogen bonds, causing a trigonal compression [4]. Another example was found in cis$\left[\mathrm{Ni}(\mathrm{acac})_{2}(\mathrm{DMF})_{2}\right]\left(\mathrm{acac}^{-}=\right.$acetylacetonate anion $)$, providing a cis-configuration due to the interligand hydrogen bonds between acetylacetonate and DMF [5].

Now we will investigate what determines the molecular conformation when there is no interligand hydrogen bond. In this study we examine a hexakis-methylamine nickel(II) complex cation $\left[\mathrm{Ni}\left(\mathrm{CH}_{3} \mathrm{NH}_{2}\right)_{6}\right]^{2+}$ [hexakis(methylamine- $\left.\kappa N\right)$ nickel(II) dication] [6]. In the previous case with hydrogen bonds, there are only four possible conformers for $\left[\mathrm{Ni}(\mathrm{DMF})_{6}\right]^{2+}$. On the other hand, in the case with no hydrogen bond, the number of possible conformers is expected to be numerous. In order to 
solve the problem, we adopt the computational group theory (CGT) method [7] for the purpose of finding all the possible conformers. In this study we find all the possible conformers based on the CGT method, and optimize the structures based on the density functional theory (DFT) method to find the most stable conformers.

\section{Computational methods}

\subsection{Finding initial conformers}

All the possible conformers were obtained based on the computational group theory (CGT) method [7], which was performed using GAP program [8] on Intel Core i7-3770 (3.40 GHz) computer, and were used as initial conformers. The GAP program used in this study is given in Appendix.

\subsection{Structural optimization}

All the initial conformers were optimized using MOPAC2012 [9] program based on the semi-empirical PM6 method [10], and the resulting conformers were optimized based on the density functional method (DFT) computation. DFT computations were performed using GAMESS program $[11,12]$ on TATARA computer at Kyushu University. Structural optimizations were performed with LC-BOP/6-31G [13]. Molecular structures were drawn using Winmostar software [14].

\section{Results and discussion}

\subsection{Finding initial conformers for hexakis- methylamine nickel(II) complex cation}

The first target in this study is to find all the possible conformers of the hexakis-methylamine nickel(II) complex cation, [Ni $\left.\left(\mathrm{CH}_{3} \mathrm{NH}_{2}\right)_{6}\right]^{2+}$ based on the computational group theory (CGT) method. In this study, we consider two cases: (1) the meridional case, in which all the methyl carbon atoms are on the meridional planes of the octahedral geometry and (2) bisected case, in which all the carbon atoms are on the bisected planes of the octahedral geometry. Note that we describe a conformer shown in Figure 1B as [ [y], [-z], [-y], [z], [-x], [x] ]; meridional planes are described as [y], [-z], and so on; bisected planes are described as $[\mathrm{y}+\mathrm{z}],[\mathrm{x}-\mathrm{z}]$, and so on. For the meridional case,

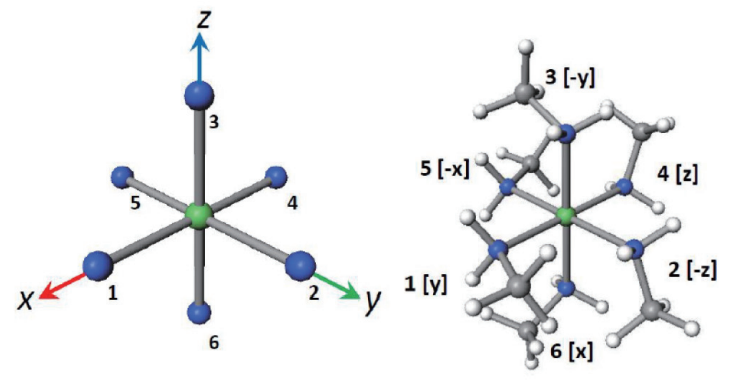

Figure 1. (A) Numbering system and (B) an example of a conformer.

among the $4^{6}(=4096)$ structures, 192 structures are found to be unique. When the sterically impossible structures are excluded, 72 structures remain, and 38 of them are diastereomers. The meridional diastereomers are summarized in Table 1 with their point groups.

In the same way for the bisected case, among the $4^{6}(=4096)$ structures, 192 are found to be unique. When the sterically unfaborable structures are excluded, 28 structures remain, and 16 of them are diastereomers. The bisected diastereomers are summarized in Table 2 with their point groups.

Tables 1 and 2 were obtained for the hexakis-methylamine nickel(II) complex cation, $\left[\mathrm{Ni}\left(\mathrm{CH}_{3} \mathrm{NH}_{2}\right)_{6}\right]^{2+}$, but it should be emphasized that these tables are universally useful when considering the hexakis ligand complex of this type.

\subsection{Structural optimization of the con- formers}

Using the semi-empirical PM6 method, all of the 54 conformers, A1-A38 and B1-B16, were optimized to obtain 24 conformers, which were converged to six conformers $\mathrm{C} 1-\mathrm{C} 6$ by the LC-BOP/6-31G method. The finally obtained six conformers are summarized in Table 3 together with energy differences, and their structures are shown in Figure 2. All the conformers were originated from the meridional structures.

The energy differences between the conformers are not so large in this case (Table 1). If the ratios of the conformers are estimated using the Boltzmann's distribution law ( $k T$ product is $0.596 \mathrm{kcal} \mathrm{mol}^{-1}$ at $300 \mathrm{~K}$ ), the ratios of conformers C1-C6 at room temperature are approximately $32 \%, 28 \%, 19 \%, 12 \%$, $7 \%$, and $2 \%$, respectively. Due to the small energy differences, conformers $\mathrm{C} 1-\mathrm{C} 5$ would be mixed at room temperature, and 
Table 1. Meridional diastereomers

\begin{tabular}{|c|c|c|}
\hline No & Example & $\begin{array}{l}\text { Point } \\
\text { Group }\end{array}$ \\
\hline $\mathrm{A} 1$ & {$[[y],[-z],[-y],[z],[-x],[x]]$} & $D_{3}$ \\
\hline A2 & [ [y], [z], [-x], [y], [z], [-x] ] & $C_{3}$ \\
\hline $\mathrm{A} 3$ & $[\mathrm{[y}],[-\mathrm{x}],[-\mathrm{x}],[-\mathrm{z}],[-\mathrm{z}],[\mathrm{y}]]$ & $C_{3}$ \\
\hline A4 & {$[\mathrm{ly}],[\mathrm{z}],[\mathrm{x}],[-\mathrm{y}],[-\mathrm{z}],[-\mathrm{x}] \mathrm{]}$} & $S_{6}$ \\
\hline A5 & {$[$ [y], [-z], [x], [-y], [z], [-x] ] } & $S_{6}$ \\
\hline A6 & {$[$ [y], [-x], [x], [-z], [-x], [x] ] } & $C_{2}$ \\
\hline A7 & [ [y], [-z], [y], [z], [-x], [-x] ] & $C_{2}$ \\
\hline A8 & [ [y], [-x], [-y], [-y], [-z], [y] ] & $C_{2}$ \\
\hline A9 & [ [y], [z], [-y], [-z], [-x], [x] ] & $C_{2}$ \\
\hline A10 & {$[[y],[-x],[x],[-y],[x],[-x]]$} & $C_{i}$ \\
\hline A11 & [ [y], [-x], [y], [-z], [-x], [y] ] & $C_{1}$ \\
\hline A12 & $[\mathrm{[y}],[-\mathrm{x}],[-\mathrm{x}],[-\mathrm{z}],[-\mathrm{x}],[\mathrm{y}]]$ & $C_{1}$ \\
\hline A13 & [ [y], [-x], [y], [-z], [z], [y] ] & $C_{1}$ \\
\hline A14 & $[\mathrm{[y}],[-\mathrm{x}],[-\mathrm{x}],[-\mathrm{y}],[-\mathrm{z}],[-\mathrm{x}]]$ & $C_{1}$ \\
\hline A15 & [ [y], [-x], [y], [-y], [-z], [y] ] & $C_{1}$ \\
\hline A16 & $[\mathrm{[y}],[-\mathrm{x}],[-\mathrm{x}],[-\mathrm{y}],[\mathrm{x}],[-\mathrm{x}]]$ & $C_{s}$ \\
\hline A17 & {$[[y],[-x],[-y],[z],[-x],[-y]]$} & $C_{1}$ \\
\hline A18 & {$[$ [y], [-z], [-x], [-y], [-z], [-x] ] } & $C_{1}$ \\
\hline A19 & $[\mathrm{ly}],[-z],[-y],[-y],[-z],[-x]]$ & $C_{1}$ \\
\hline A20 & $[\mathrm{[y}],[-z],[y],[-y],[-z],[-x]]$ & $C_{1}$ \\
\hline A21 & $[\mathrm{[y}],[\mathrm{z}],[-\mathrm{x}],[-\mathrm{y}],[-\mathrm{z}],[-\mathrm{x}]]$ & $C_{1}$ \\
\hline A22 & $[\mathrm{yy}],[-\mathrm{x}],[\mathrm{x}],[-\mathrm{z}],[-\mathrm{x}],[\mathrm{y}]]$ & $C_{1}$ \\
\hline A23 & {$[[y],[-x],[-y],[z],[-x],[x]]$} & $C_{1}$ \\
\hline A24 & $[\mathrm{ly}],[-\mathrm{x}],[\mathrm{y}],[-\mathrm{z}],[-\mathrm{x}],[\mathrm{x}]]$ & $C_{1}$ \\
\hline A25 & [ [y], [z], [-x], [-z], [z], [-y] ] & $C_{1}$ \\
\hline A26 & $[\mathrm{yy}],[-\mathrm{z}],[-\mathrm{x}],[-\mathrm{y}],[\mathrm{x}],[-\mathrm{x}]]$ & $C_{1}$ \\
\hline A27 & [ [y], [-z], [y], [-z], [-x], [x] ] & $C_{1}$ \\
\hline A28 & {$[[y],[-x],[-y],[-y],[-z],[-x]]$} & $C_{1}$ \\
\hline A29 & {$[$ [y], [-z], [-y], [-z], [-x], [x] ] } & $C_{1}$ \\
\hline $\mathrm{A} 30$ & $[\mathrm{[y}],[-\mathrm{x}],[\mathrm{y}],[-\mathrm{y}],[-\mathrm{z}],[-\mathrm{x}]]$ & $C_{1}$ \\
\hline A31 & $[\mathrm{cy}],[-\mathrm{x}],[\mathrm{x}],[-\mathrm{y}],[-\mathrm{z}],[-\mathrm{x}]]$ & $C_{1}$ \\
\hline A32 & {$[$ [y], [-x], [-x], [-z], [z], [-y] ] } & $C_{1}$ \\
\hline A33 & [ [y], [-x], [y], [-y], [z], [-x] ] & $C_{1}$ \\
\hline A34 & {$[$ [y], [-z], [y], [-y], [x], [-x] ] } & $C_{1}$ \\
\hline A35 & {$[[y],[-x],[x],[-y],[z],[-x]]$} & $C_{1}$ \\
\hline A36 & $[\mathrm{[y}],[-\mathrm{x}],[-\mathrm{y}],[-\mathrm{y}],[\mathrm{x}],[-\mathrm{x}]]$ & $C_{1}$ \\
\hline A37 & {$[[\mathrm{y}],[-z],[-\mathrm{x}],[-\mathrm{y}],[\mathrm{x}],[-\mathrm{y}]]$} & $C_{1}$ \\
\hline A38 & $[\mathrm{ly}],[\mathrm{z}],[-\mathrm{x}],[-\mathrm{y}],[\mathrm{x}],[-\mathrm{y}]]$ & $C_{1}$ \\
\hline
\end{tabular}

the dominant species is thought to be changeable by environment.

\subsection{Structural features of the most stable conformers}

The most stable conformer $\mathrm{C} 1$ has the lowest symmetry; how- ever, we found a helical alignment of the ligands around the central nickel(II) ion through $\mathrm{N}-\mathrm{C} \cdot \cdot(\cdot \cdot \mathrm{N}-\mathrm{C} \cdot \cdot)_{4} \cdot \cdot \mathrm{N}-\mathrm{C}$ as shown in Figure 3. The helical alignment seems to be suitable for avoiding steric repulsion between adjacent ligands, and this must be the reason why such a low symmetric structure could be the most stable. This type of structure was not found in the previous $\left[\mathrm{Ni}(\mathrm{DMF})_{6}\right]^{2+}$ complex [4]. The second and the third most stable structures (conformers C2 and C3) were pseudo$S_{6}$ and pseudo- $D_{3}$ structures, respectively. In the previous $[\mathrm{Ni}$ $\left.(\mathrm{DMF})_{6}\right]^{2+}$ complex [4], $S_{6}$ and $D_{3}$ conformers were the most stable and the second most stable conformers, respectively, and the energy difference was $\sim 2 \mathrm{kcal} \mathrm{mol}^{-1}$. In $\left[\mathrm{Ni}(\mathrm{DMF})_{6}\right]^{2+}$, interligand hydrogen bonds stabilize the $S_{6}$ conformer, but at the same time, the conformer is suitable for avoiding steric repulsion between the ligands. In conformers $\mathrm{C} 2$ and $\mathrm{C} 3$, trigonal compression was observed along the pseudo-trigonal axis. All of the other structures C4-C6 have $C_{2}$ symmetries, but their structures were slightly different from each other. The number of resulting conformers for $\left[\mathrm{Ni}\left(\mathrm{CH}_{3} \mathrm{NH}_{2}\right)_{6}\right]^{2+}$ (six) is larger than that for $\left[\mathrm{Ni}(\mathrm{DMF})_{6}\right]^{2+}$ (four), presumably because the degrees of freedom for $\left[\mathrm{Ni}(\mathrm{DMF})_{6}\right]^{2+}$ are smaller due to the interligand hydrogen bonds.

\subsection{Conformational analysis for a zinc(II) derivative}

In order to ascertain the tendencies of the conformers obtained for $\left[\mathrm{Ni}\left(\mathrm{CH}_{3} \mathrm{NH}_{2}\right)_{6}\right]^{2+}$, conformational analysis was conducted for a zinc(II) derivative, $\left[\mathrm{Zn}\left(\mathrm{CH}_{3} \mathrm{NH}_{2}\right)_{6}\right]^{2+}$. Using the PM6 and LC-BOP/6-31G methods, all 54 conformers were optimized to obtain eight conformers. The final eight conformers D1-D8 are summarized in Table 4, and their structures are shown in Figure 4. Conformers D1-D7 were originated from the meridional structures, but conformer D8 was from a bisected structure. The number of conformers for the zinc derivative (eight) is larger than that for the nickel derivative; $C_{i}(\mathrm{D} 5)$ and $D_{3 d}$ (D8) conformers were obtained only for the zinc derivative. The structural variety of the zinc derivative is presumably due to the fact that $\mathrm{Zn} \cdots \mathrm{N}$ distances $(\sim 2.23 \AA)$ are larger than $\mathrm{Ni} \cdots \mathrm{N}$ distances $(\sim 2.17 \AA)$, and the structures are thought to be less restricted for the zinc derivative.

The most stable conformer D1 has the helical $C_{1}$ symmetry as conformer $\mathrm{C} 1$. The second most stable conformer $\mathrm{D} 2$ and the 
Table 2. Bisected diastereomers

\begin{tabular}{clc}
\hline No & \multicolumn{1}{c}{ Example } & $\begin{array}{c}\text { Point } \\
\text { Group }\end{array}$ \\
\hline B1 & {$[[\mathrm{y}+\mathrm{z}],[\mathrm{x}-\mathrm{z}],[\mathrm{x}-\mathrm{y}],[-\mathrm{y}-\mathrm{z}],[-\mathrm{x}+\mathrm{z}],[-\mathrm{x}+\mathrm{y}]]$} & $D_{3 d}$ \\
B2 & {$[[\mathrm{y}+\mathrm{z}],[-\mathrm{x}-\mathrm{z}],[\mathrm{x}-\mathrm{y}],[\mathrm{y}+\mathrm{z}],[-\mathrm{x}-\mathrm{z}],[\mathrm{x}-\mathrm{y}]]$} & $D_{3}$ \\
B3 & {$[[\mathrm{y}+\mathrm{z}],[-\mathrm{x}+\mathrm{z}],[-\mathrm{x}-\mathrm{y}],[-\mathrm{y}-\mathrm{z}],[\mathrm{x}-\mathrm{z}],[\mathrm{x}+\mathrm{y}]]$} & $S_{6}$ \\
B4 & {$[[\mathrm{y}+\mathrm{z}],[\mathrm{x}-\mathrm{z}],[-\mathrm{x}+\mathrm{y}],[-\mathrm{y}-\mathrm{z}],[-\mathrm{x}+\mathrm{z}],[\mathrm{x}-\mathrm{y}]]$} & $C_{2 h}$ \\
B5 & {$[[\mathrm{y}+\mathrm{z}],[-\mathrm{x}+\mathrm{z}],[\mathrm{x}-\mathrm{y}],[-\mathrm{y}-\mathrm{z}],[-\mathrm{x}+\mathrm{z}],[\mathrm{x}-\mathrm{y}]]$} & $C_{2}$ \\
B6 & {$[[\mathrm{y}+\mathrm{z}],[-\mathrm{x}+\mathrm{z}],[\mathrm{x}-\mathrm{y}],[\mathrm{y}-\mathrm{z}],[-\mathrm{x}+\mathrm{z}],[-\mathrm{x}-\mathrm{y}]]$} & $C_{2}$ \\
B7 & {$[[\mathrm{y}+\mathrm{z}],[\mathrm{x}-\mathrm{z}],[-\mathrm{x}-\mathrm{y}],[-\mathrm{y}-\mathrm{z}],[\mathrm{x}+\mathrm{z}],[-\mathrm{x}+\mathrm{y}]]$} & $C_{2}$ \\
B8 & {$[[\mathrm{y}+\mathrm{z}],[-\mathrm{x}+\mathrm{z}],[-\mathrm{x}-\mathrm{y}],[-\mathrm{y}-\mathrm{z}],[\mathrm{x}+\mathrm{z}],[\mathrm{x}-\mathrm{y}]]$} & $C_{2}$ \\
B9 & {$[[\mathrm{y}+\mathrm{z}],[-\mathrm{x}+\mathrm{z}],[\mathrm{x}-\mathrm{y}],[\mathrm{y}-\mathrm{z}],[-\mathrm{x}-\mathrm{z}],[\mathrm{x}-\mathrm{y}]]$} & $C_{2}$ \\
B10 & {$[[\mathrm{y}+\mathrm{z}],[\mathrm{x}-\mathrm{z}],[-\mathrm{x}+\mathrm{y}],[-\mathrm{y}-\mathrm{z}],[-\mathrm{x}+\mathrm{z}],[-\mathrm{x}+\mathrm{y}]]$} & $C_{s}$ \\
B11 & {$[[\mathrm{y}+\mathrm{z}],[-\mathrm{x}-\mathrm{z}],[\mathrm{x}-\mathrm{y}],[-\mathrm{y}-\mathrm{z}],[-\mathrm{x}+\mathrm{z}],[\mathrm{x}-\mathrm{y}]]$} & $C_{1}$ \\
B12 & {$[[\mathrm{y}+\mathrm{z}],[-\mathrm{x}+\mathrm{z}],[\mathrm{x}-\mathrm{y}],[\mathrm{y}-\mathrm{z}],[-\mathrm{x}+\mathrm{z}],[\mathrm{x}-\mathrm{y}]]$} & $C_{1}$ \\
B13 & {$[[\mathrm{y}+\mathrm{z}],[-\mathrm{x}-\mathrm{z}],[-\mathrm{x}+\mathrm{y}],[-\mathrm{y}+\mathrm{z}],[-\mathrm{x}-\mathrm{z}],[\mathrm{x}+\mathrm{y}]]$} & $C_{1}$ \\
B14 & {$[[\mathrm{y}+\mathrm{z}],[-\mathrm{x}+\mathrm{z}],[-\mathrm{x}-\mathrm{y}],[-\mathrm{y}-\mathrm{z}],[\mathrm{x}+\mathrm{z}],[-\mathrm{x}+\mathrm{y}]]$} & $C_{1}$ \\
B15 & {$[[\mathrm{y}+\mathrm{z}],[-\mathrm{x}-\mathrm{z}],[-\mathrm{x}+\mathrm{y}],[-\mathrm{y}-\mathrm{z}],[-\mathrm{x}+\mathrm{z}],[\mathrm{x}-\mathrm{y}]]$} & $C_{1}$ \\
\hline
\end{tabular}

Table 3. Optimized diastereomers for $\left[\mathrm{Ni}\left(\mathrm{CH}_{3} \mathrm{NH}_{2}\right)_{6}\right]^{2+}$.

\begin{tabular}{cccc}
\hline No & Point Group & $\begin{array}{c}\text { Initial } \\
\text { structure }\end{array}$ & $\begin{array}{c}\text { Energy } \\
\text { difference }\end{array}$ \\
\hline C1 & $C_{1}$ & $\mathrm{~A} 37\left(C_{1}\right)$ & 0.000 \\
C2 & pseudo- $S_{6}\left(C_{1}\right)$ & $\mathrm{A} 5\left(S_{6}\right)$ & 0.094 \\
C3 & pseudo- $D_{3}\left(C_{2}\right)$ & $\mathrm{A} 1\left(D_{3}\right)$ & 0.310 \\
C4 & pseudo- $C_{2}\left(C_{1}\right)$ & $\mathrm{A} 9\left(C_{2}\right)$ & 0.617 \\
C5 & $C_{2}$ & $\mathrm{~A} 6\left(C_{2}\right)$ & 0.929 \\
C6 & $C_{2}$ & $\mathrm{~A} 8\left(C_{2}\right)$ & 1.535 \\
\hline
\end{tabular}

$a$ kcal $\mathrm{mol}^{-1}$.

Table 4. Optimized diastereomers for $\left[\mathrm{Zn}\left(\mathrm{CH}_{3} \mathrm{NH}_{2}\right)_{6}\right]^{2+}$.

\begin{tabular}{|c|c|c|c|}
\hline No & Point Group & $\begin{array}{c}\text { Initial } \\
\text { structure }\end{array}$ & $\begin{array}{c}\text { Energy } \\
\text { difference }^{a}\end{array}$ \\
\hline D1 & $C_{1}$ & $\mathrm{~A} 37\left(C_{1}\right)$ & 0.00000 \\
\hline D2 & pseudo- $S_{6}\left(C_{1}\right)$ & $\mathrm{A} 5\left(S_{6}\right)$ & 0.32615 \\
\hline D3 & $C_{2}$ & $\mathrm{~A} 8\left(C_{2}\right)$ & 0.46001 \\
\hline D4 & pseudo- $D_{3}\left(C_{2}\right)$ & $\mathrm{A} 1\left(D_{3}\right)$ & 0.61638 \\
\hline D5 & $C_{i}$ & $\mathrm{~A} 10\left(C_{i}\right)$ & 0.81220 \\
\hline D6 & $C_{2}$ & $\mathrm{~A} 6\left(C_{2}\right)$ & 0.82813 \\
\hline D7 & pseudo- $C_{2}\left(C_{1}\right)$ & A9 $\left(C_{2}\right)$ & 0.97887 \\
\hline D8 & $D_{3 d}$ & $\mathrm{~B} 1\left(D_{3 d}\right)$ & 14.40083 \\
\hline
\end{tabular}

$a$ kcal mol ${ }^{-1}$.
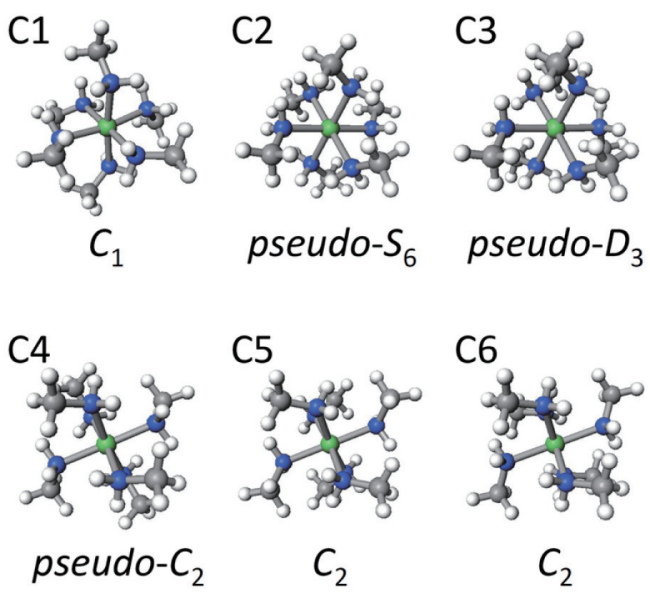

Figure 2. Optimized conformers for $\left[\mathrm{Ni}\left(\mathrm{CH}_{3} \mathrm{NH}_{2}\right)_{6}\right]^{2+}$ complex cation (LC-BOP/6-31G).

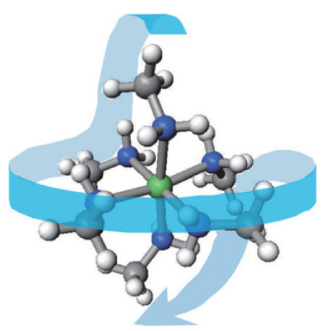

Figure 3. Helical alignment of the ligands in the most stable conformer $\mathrm{C} 1$ for $\left[\mathrm{Ni}\left(\mathrm{CH}_{3} \mathrm{NH}_{2}\right)_{6}\right]^{2+}$.

fourth most stable conformer D4 have the pseudo- $S_{6}$ and pseudo- $D_{3}$ symmetries, respectively, and they correspond to conformers $\mathrm{C} 2$ and $\mathrm{C} 3$. Conformers D3, D6, and D7 correspond to conformers $\mathrm{C} 4, \mathrm{C} 5$, and $\mathrm{C} 6$, respectively. The order of the conformers for the zinc derivative is slightly different from that for the nickel derivative, but the structures of the most stable structures D1 and $\mathrm{C} 1$ are very similar.

The energy differences for the zinc derivative are not so large (Table 4). This is also the case for the nickel derivative. If the Boltzmann's distribution law is used, the ratios of conformers D1-D8 at $300 \mathrm{~K}$ are approximately $32 \%, 19 \%, 15 \%, 11 \%, 8 \%$, $8 \%, 6 \%$, and $0 \%$, respectively. Due to the small energy differences, conformers D1-D7 would be mixed at room temperature. Due to the small energy differences, conformers D1-D7 would be mixed at room temperature, and the dominant species is thought to be changeable by environment. 


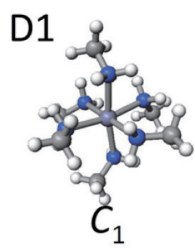

D2

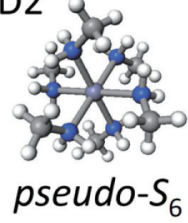

D3

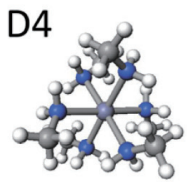

pseudo- $D_{3}$

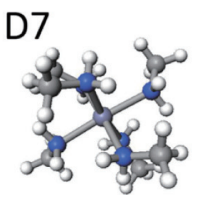

pseudo- $C_{2}$

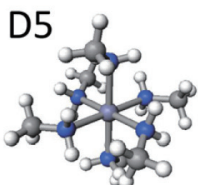

$C_{i}$

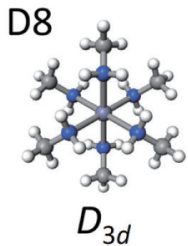

Figure 4. Optimized conformers for $\left[\mathrm{Zn}\left(\mathrm{CH}_{3} \mathrm{NH}_{2}\right)_{6}\right]^{2+}$ complex cation (LC-BOP/6-31G).

\section{Concluding remarks}

In this study, possible conformers were obtained for [ $\mathrm{Ni}$ $\left.\left(\mathrm{CH}_{3} \mathrm{NH}_{2}\right)_{6}\right]^{2+}$ and $\left[\mathrm{Zn}\left(\mathrm{CH}_{3} \mathrm{NH}_{2}\right)_{6}\right]^{2+}$ complex cations on the basis of the CGT method. Based on the DFT computations six stable conformers were obtained for $\left[\mathrm{Ni}^{(}\left(\mathrm{CH}_{3} \mathrm{NH}_{2}\right)_{6}\right]^{2+}$, and eight for $\left[\mathrm{Zn}\left(\mathrm{CH}_{3} \mathrm{NH}_{2}\right)_{6}\right]^{2+}$. The most stable conformers for the both complex cations had the helical $C_{1}$ symmetry, and the helical alignment of the ligands is thought to be suitable for avoiding steric repulsion between the ligands. Since the energy differences were not so large for both complex cations, some of the conformers would be mixed at room temperature, and the dominant species would be changeable by environment.

Financial support by Yamagata University is gratefully acknowledged. A copy of the MOPAC2012 program was provided by Professor J. J. P. Stewart. The technical support on Tatara computer was provided by Dr. Yuichi Inadomi at Kyushu University

\section{References}

[1] R. Boča, Coord. Chem. Rev. 248, 757 (2004). [CrossRef]

[2] O. Kahn, Molecular Magnetism, VCH (1993).

[3] R. Yamaguchi, M. Yamasaki, H. Sakiyama, X-ray Struct., Anal. Online, 27, 71 (2011).

[4] K. Abe, Y. Chiba, R. Yamaguchi, H. Sakiyama, J. Comput. Chem. Jpn. 12, 168 (2013). [CrossRef]

[5] Md.Kudrat-E-Zahan, Y. Nishida, H. Sakiyama, Inorg. Chim. Acta, 363, 168 (2010).

[6] G. Kenessey, B. R. Carson, J. R. Allan, T. Wadsten, G. Liptay, J. Therm. Anal. 50, 167 (1997). [CrossRef]

[7] F. Derek, Holt, Handbook of Computational Group Theory. In the series 'Discrete Mathematics and its Applications', Chapman \& Hall/CRC 2005, xvi +514 p.

[8] The GAP Group, GAP-Groups, Algorithms, and Programming, Version 4.7.4; 2014. (http://www.gap-system. org)

[9] J. J. P. Stewart, http://openmopac.net/MOPAC2012.html/.

[10] J. J. P. Stewart, J. Mol. Model. 10.1007/s00894-0070233-4

[11] M. W. Schmidt, K. K. Baldridge, J. A. Boatz, S. T. Elbert, M. S. Gordon, J. H. Jensen, S. Koseki, N. Matsunaga, K. A. Nguyen, S. Su, T. L. Windus, M. Dupuis, J. A. Montgomery, J. Comput. Chem. 14, 1347 (1993). [CrossRef]

[12] M. S. Gordon, M. W. Schmidt, Advances in electronic structure theory, Elsevier (2005).

[13] Y. Tawada, T. Tsuneda, S. Yanagisawa, T. Yanai, K. Hirao, J. Chem. Phys. 120, 8425 (2004). [Medline] [CrossRef]

[14] N. Senda, 2008 http://winmostar.com/.

\section{Appendix}

[GAP program for finding initial conformers]

$1:=3 ;$

$\mathrm{s}:=\mathrm{ER}(2) ;$

$\mathrm{Mx}:=[[1,0,0],[0,0,1],[0,-1,0]] ; ;$

Mz: $=[[0,1,0],[-1,0,0],[0,0,1]] ;$

$\mathrm{Mm}:=[[1,0,0],[0,1,0],[0,0,-1]] ;$

$\mathrm{x}:=[1,0,0] ;$

$\mathrm{y}:=[0,1,0] ;$

$\mathrm{z}:=[0,0,1] ;$

$\mathrm{x} 1:=[\mathrm{s}, 0,0]^{*} \mathrm{ER}(2) / 2 ;$

$\mathrm{y} 1:=[0, \mathrm{~s}, 0]^{*} \operatorname{ER}(2) / 2 ;$

$\mathrm{z} 1:=[0,0, \mathrm{~s}]^{*} \operatorname{ER}(2) / 2 ;$

Pxa: $=[\mathrm{x}+\mathrm{y} 1+\mathrm{z} 1, \mathrm{x}+\mathrm{y} 1-\mathrm{z} 1, \mathrm{x}-\mathrm{y} 1-\mathrm{z} 1, \mathrm{x}-\mathrm{y} 1+\mathrm{z} 1] ; ;$ 


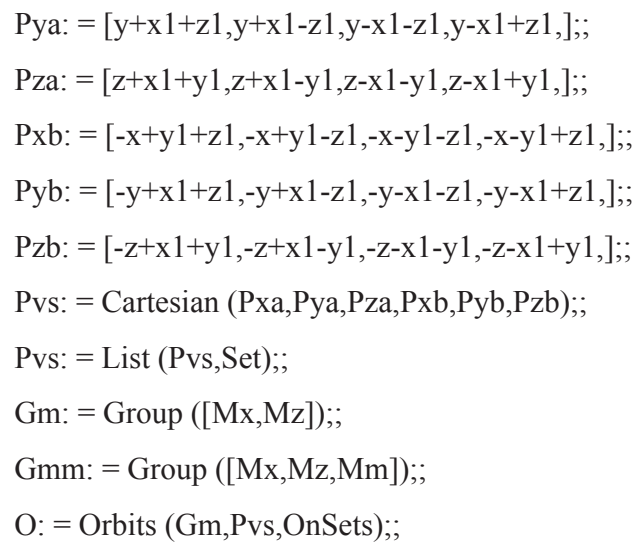

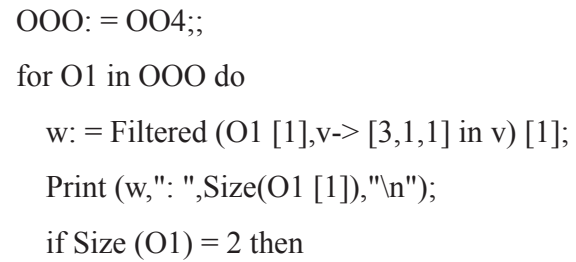

